\title{
miRNA589 Regulates Epithelial-Mesenchymal Transition in Human Peritoneal Mesothelial Cells
}

\author{
Ke Zhang, ${ }^{1}$ Hao Zhang, ${ }^{1}$ Xun Zhou, ${ }^{2}$ Wen-bin Tang, ${ }^{2}$ Li Xiao, ${ }^{2}$ Ying-hong Liu, \\ Hong Liu, ${ }^{2}$ You-ming Peng, ${ }^{2}$ Lin Sun, ${ }^{2,3}$ and Fu-you Liu ${ }^{2}$ \\ ${ }^{1}$ Department of Nephrology and Renal Institute, The Third Xiangya Hospital, Central South University, Changsha, \\ Hunan 410013, China \\ ${ }^{2}$ Department of Nephrology and Renal Institute, The Second Xiangya Hospital, Central South University, Changsha, \\ Hunan 410011, China \\ ${ }^{3}$ Department of Pathology and Medicine, Feinberg School of Medicine, Northwestern University, Chicago, IL 60611, USA
}

Correspondence should be addressed to Lin Sun, sunlinnwu11@163.com and Fu-you Liu, lfy410@yahoo.com.cn

Received 24 April 2012; Revised 30 June 2012; Accepted 12 July 2012

Academic Editor: Gary E. Gallick

Copyright ( $) 2012$ Ke Zhang et al. This is an open access article distributed under the Creative Commons Attribution License, which permits unrestricted use, distribution, and reproduction in any medium, provided the original work is properly cited.

\begin{abstract}
Background. microRNA (miRNA, miR) are thought to interact with multiple mRNAs which are involved in the EMT process. But the role of miRNAs in peritoneal fibrosis has remained unknown. Objective. To determine if miRNA589 regulates the EMT induced by TGF $\beta 1$ in human peritoneal mesothelial cell line (HMrSV5 cells). Methods. 1. Level of miR589 was detected in both human peritoneal mesothelial cells (HPMCs) isolated from continuous ambulatory peritoneal dialysis (CAPD) patients' effluent and HMrSV5 cells treated with or without TGF $\beta 1$. 2. HMrSV5 cells were divided into three groups: control group, TGF $\beta 1$ group, and pre-miR-589+TGF $\beta 1$ group. The level of miRNA589 was determined by realtime PCR. The expressions of ZO-1, vimentin, and Ecadherin in HPMCs were detected, respectively. Results. Decreased level of miRNA589 was obtained in either HPMCs of long-term CAPD patients or HMrSV 5 cells treated with TGF $\beta 1$. In vitro, TGF $\beta 1$ led to upregulation of vimentin and downregulation of ZO-1 as well as E-cadherin in HMrSV5 cells, which suggested EMT, was induced. The changes were accompanied with notably decreased level of miRNA589 in HMrSV5 cells treated with TGF $\beta 1$. Overexpression of miRNA589 by transfection with pre-miRNA589 partially reversed these EMT changes. Conclusion. miRNA589 mediates TGF $\beta 1$ induced EMT in human peritoneal mesothelial cells.
\end{abstract}

\section{Introduction}

In the past 20 years, peritoneal dialysis (PD) has become an alternative to hemodialysis for treatment of end stage of renal diseases (ESRD). Unfortunately, peritoneal fibrosis is an almost invariable consequence of peritoneal dialysis (PD). Recent evidence suggests that the epithelial to mesenchymal transition (EMT) of human peritoneal mesothelial cells (HPMCs) is an early event during PD and is associated with high peritoneal transport and it is a key process leading to peritoneal fibrosis and function deterioration [1-3]. Recent data suggest that TGF $\beta 1$ serves as a source of EMT and induces the EMT process in various epithelial cells and tissues fibrosis in vitro and in vivo [4-7]. The mechanism by which TGF $\beta 1$ elicits EMT has been a major topic of current research on fibrosis.

The microRNAs (miRNA, miR) are a class of short noncoding RNAs that are evolutionarily conserved, and function as negative regulators of gene expression [8, 9]. It has been well established that miRNAs play key roles in modulating gene expression during embryonic development and cell differentiation on posttranscriptional level. To date, more than 1000 human miRNAs have been experimentally identified, and it is estimated that they regulate more than one-third of cellular messenger RNA by binding to the $3^{\prime}$ untranslated regions (UTRs) of their target genes or by inducing mRNA degradation [10]. Accumulating evidence has linked the deregulated expression patterns of miRNAs to a variety of diseases, such as cancer, cardiovascular diseases, 


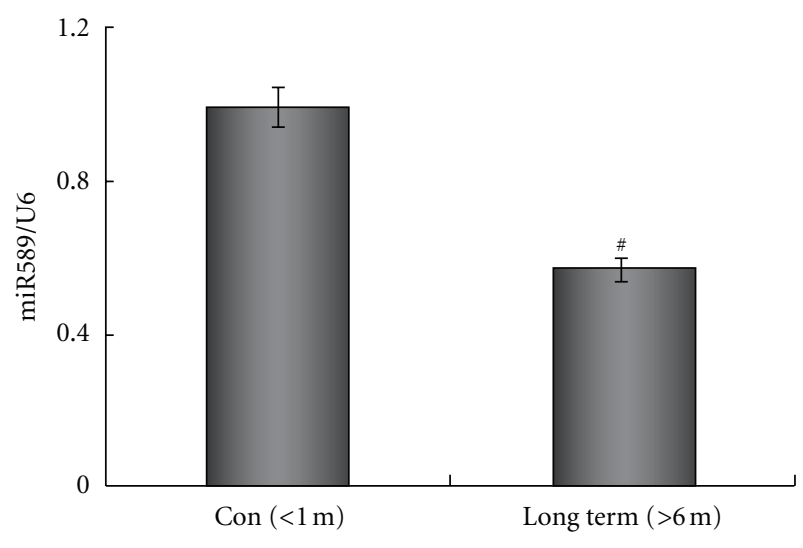

Figure 1: Expression of miRNA589 in HPMCs isolated from CAPD patients effluents, as assessed by realtime PCR. The bar graphs represent the $2^{-\Delta \Delta \mathrm{C}_{\mathrm{T}}}$ value of miRNA589 relative to U6 $\left({ }^{\#} P<0.05\right.$ versus the control patients). The data are presented as the mean ratio $\pm \mathrm{SD}$, respectively. The ratio of miRNA in long term CAPD group was $0.5765 \pm 0.0546$. ${ }^{\#}$ versus control group, $P<0.01$.

and fibrosis. Recent evidence suggested miRNAs play a pivotal role in TGF $\beta 1$ induced EMT [11-13]. Kato et al. recently showed that the level of miRNA192 were upregulated by TGF- $\beta 1$ in mouse mesangial cells, and miRNA192 plays a pivotal role in diabetic nephropathy, mediated via controlling TGF- $\beta$-induced collagen I expression by downregulating Ebox repressors [14]. Zavadil revealed that miRNA-200 and miRNA-205 were downregulated during TGF $\beta$ mediated EMT in Madin Darby canine kidney (MDCK) epithelial cells, which regulated EMT by targeting the E-cadherin transcriptional repressors ZEB1 and SIP1 [15]. Since miRNAs were distributed with tissue specificity, the role of miRNAs in EMT of HPMC has remained unknown. Our unpublished data showed that more than 90 miRNAs were differential expression in HPMCs of patients undergoing long term CAPD. These findings led us to determine the effect of miRNAs on HPMCs undergoing EMT and its mechanism.

Our pre-experiment revealed the profile of miRNAs in both HMrSV5 cells treated with TGF $\beta 1$ and HPMCs isolated from effluents of patients undergoing long term CAPD. Remarkable miRNA profile variation was obtained, compared to the control, which suggested miRNAs might correlate with EMT in HPMCs. We selected miRNA589 as the target miRNA account of its expression level and downstream target mRNA analysis. To date, there have been no published data on miRNA589 expression patterns in HPMCs. Our investigation is aimed to determine the role of miRNA589 in regulating EMT induced by TGF $\beta 1$.

\section{Materials and Methods}

2.1. Patients and Human Peritoneal Mesothelial Cells Isolated from Peritoneal Dialysis Solution. HPMCs from effluent were obtained by centrifugation of dialysis fluid taken randomly from 12 clinically stable patients undergoing CAPD from the Third Xiangya Hospital, Central South University, China. 6 of them undergoing CAPD for more than 6 months

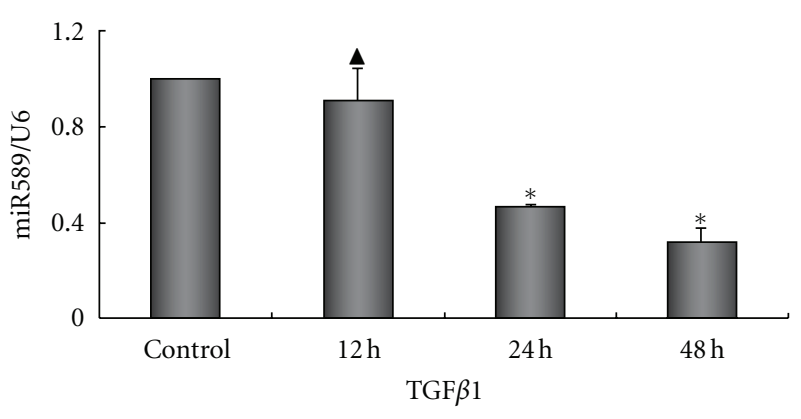

Figure 2: Expression of miRNA589 in HMrSV5 cells following exposure toTGF $\beta 1$ ( $5 \mathrm{ng} / \mathrm{ml}, 0-48 \mathrm{hr})$, as assessed by realtime PCR. The bar graphs show the $2^{-\Delta \Delta \mathrm{C}_{\mathrm{T}}}$ value of miRNA589 relative to that of U6 in HMrSV5 cells following exposure to TGF $\beta 1$ ( $5 \mathrm{ng} / \mathrm{ml}$, $0-48 \mathrm{hr}$ ). Expression of miRNA589 decreased in a time-dependent manner in HMrSV 5 cells treated with TGF $\beta 1$ (column 2, 3, 4). The $2^{-\Delta \Delta \mathrm{C}_{\mathrm{T}}}$ of miRNA589 expression level of HPMCs treated with TGF$\beta 1$ for $24 \mathrm{~h}$ and $48 \mathrm{~h}$ were $0.4610 \pm 0.01608(P<0.05)$ and $0.3187 \pm$ $0.06036(P<0.05)$ as the mean ratio $\pm \mathrm{SD}$, respectively. $\Delta P>0.05$ versus control group, ${ }^{*} P<0.05$ versus control group.

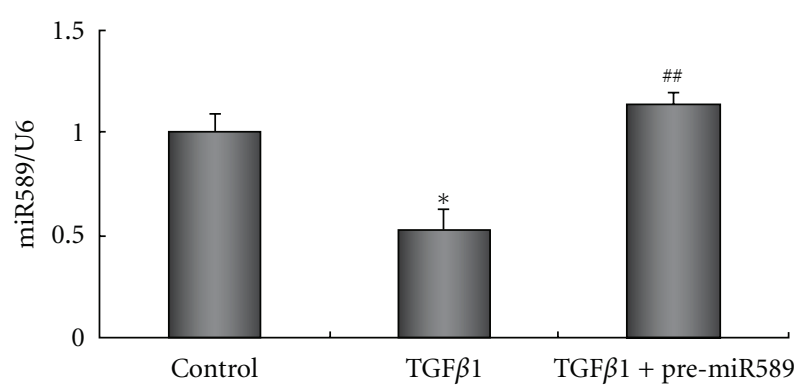

FIGURE 3: Effect of pre-miRNA589 on expression of miR589 in HMrSV 5 cells following exposure to TGF $\beta 1(5 \mathrm{ng} / \mathrm{ml}, 24 \mathrm{hr})$. The bar graphs show the $2^{-\Delta \Delta \mathrm{C}_{\mathrm{T}}}$ value of miRNA589 relative to that of U6 in each group. The level of miRNA 589 was decreased in HMrSV 5 cells treated with TGF $\beta 1$. (column 2), and this effect was abolished following transfection with pre-miR589 (column 3 ). ${ }^{*} P<$ 0.05 versus control group, ${ }^{\#} P<0.01$ versus TGF- $\beta 1$ treated group.

and the other patients for less than 1 month $(n=6$, control). All the HPMCs were obtained before the first episode of peritonitis occurred. HPMCs were maintained in a defined medium (1:1 mixture of DMEM and Ham's F12 containing $15 \%$ FBS, penicillin $(100 \mathrm{U} / \mathrm{ml})$, streptomycin $(100 \mu \mathrm{g} / \mathrm{ml})$, insullin $(0.5 \mu \mathrm{g} / \mathrm{ml})$, transferrin $(5 \mu \mathrm{g} / \mathrm{ml})$, and hydrocortisone $(1 \mu \mathrm{g} / \mathrm{ml}))$ at $37^{\circ} \mathrm{C}$. After achieving $80 \%$ cell confluency, total RNAs and miRNAs were isolated. The morphology of HPMCs was investigated by inverted microscope.

The study was approved by the ethics committee of the Third Xiangya Hospital, Central South University in Changsha Hunan, China Oral informed consent was obtained from all donors.

2.2. In Vitro Cell Culture Studies. HMrSV5 cells, presented by Pierre Ronco, Tenon Hospital, Paris, were maintained in 

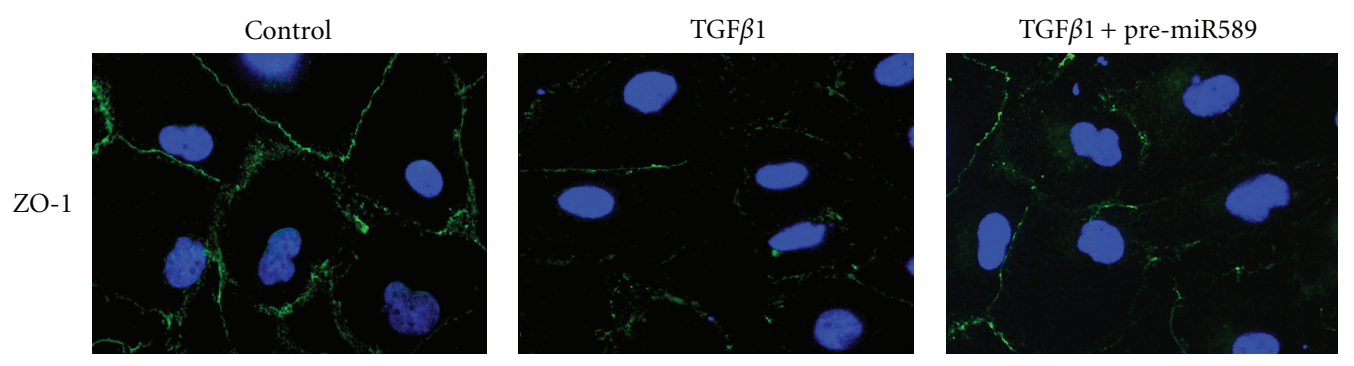

(a)
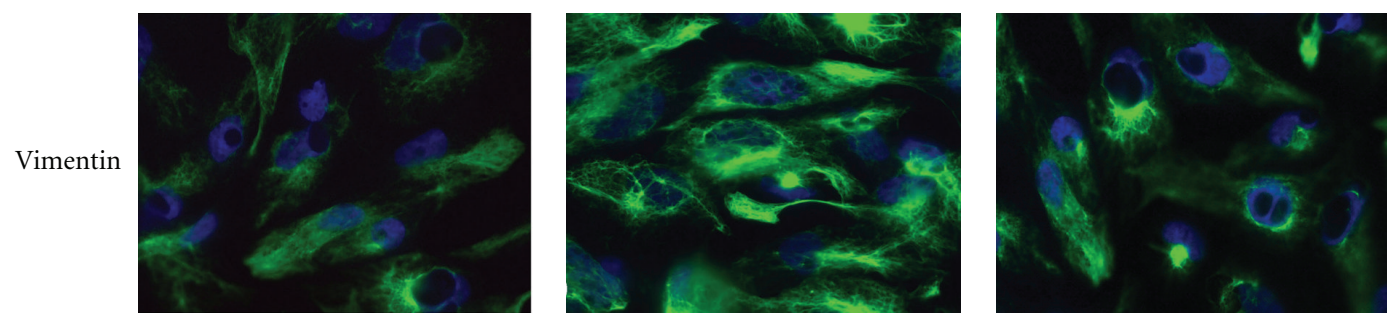

(b)

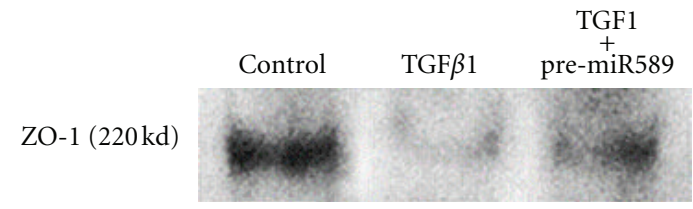

$\beta$-actin (43kd)

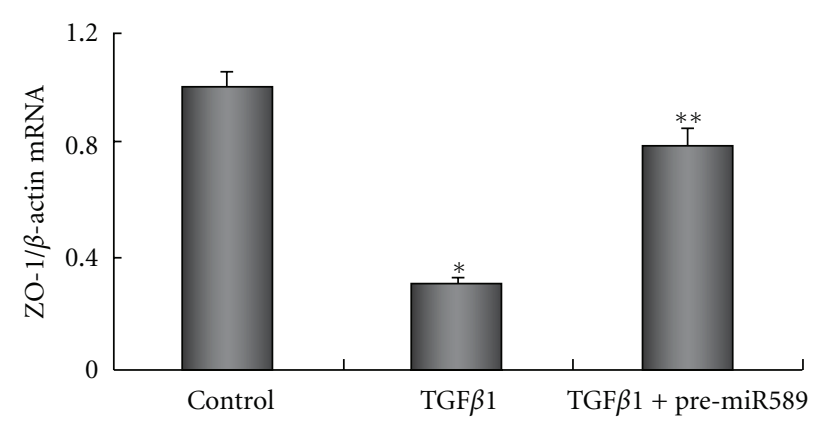

(c)

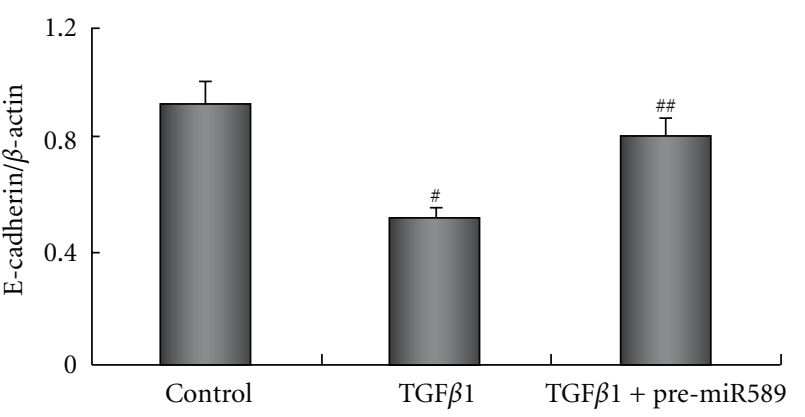

(e)

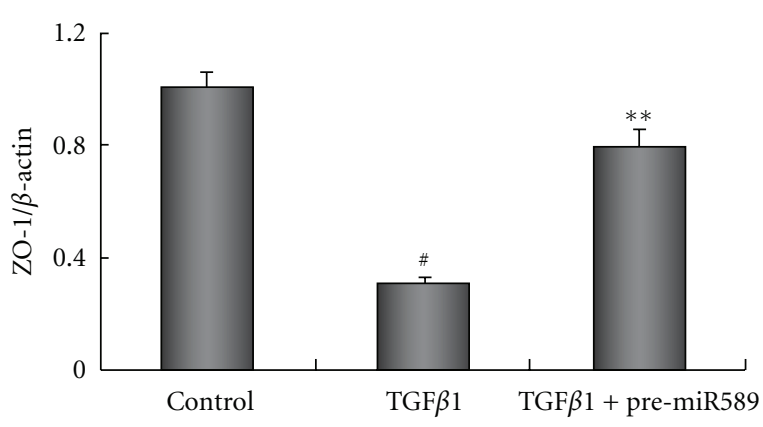

(d)
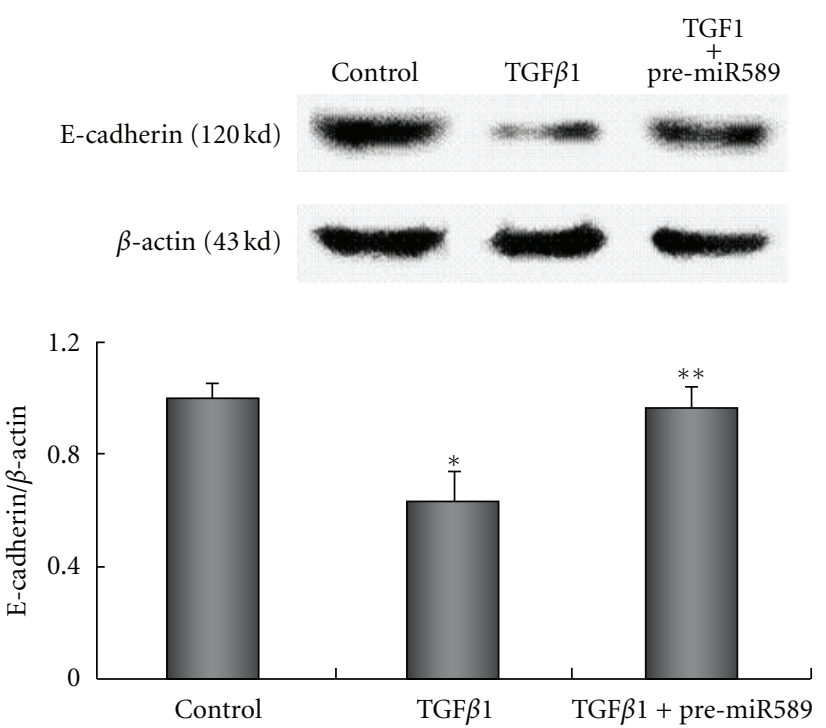

(f)

Figure 4: Continued. 


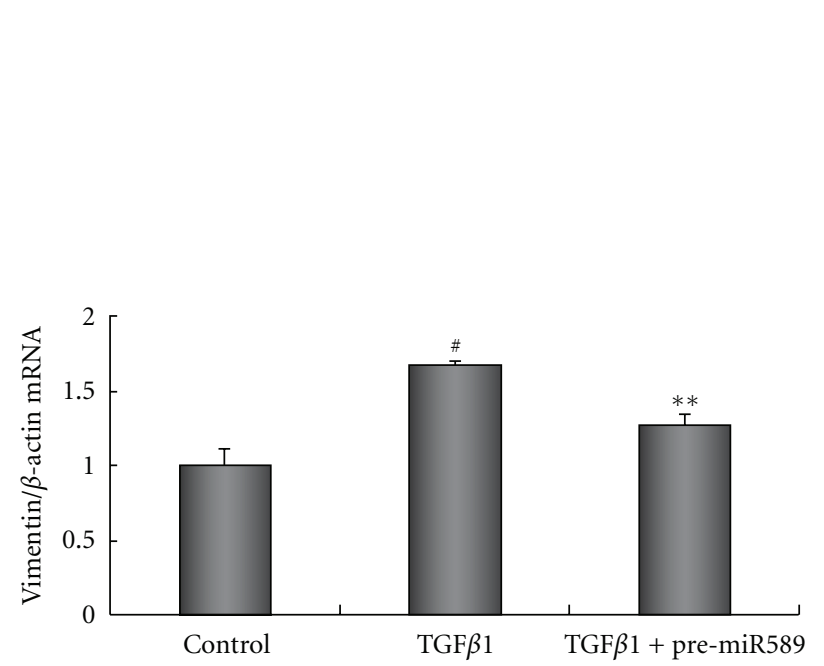

(g)
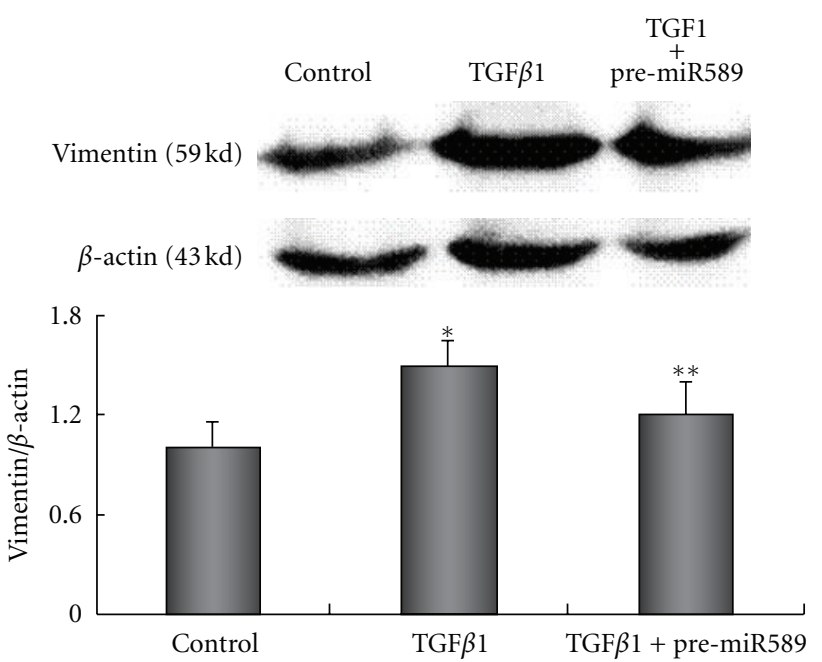

(h)

FIGURE 4: Effect of pre-miRNA589 on expression ZO-1, E-cadherin, and vimentin in HMrSV5 cells following exposure to TGF $\beta 1$ (5 ng/ml, $24 \mathrm{hr}$ ). Panel (a) and (b) showed the ZO-1 and vimentin protein expression detected by immunofluerence. Fluorescent confocal microscopy for ZO- 1 and vimentin confirmed that pretreatment of pre-miR589 normalized the EMT changes induced by TGF $\beta 1$ in HMrSV5 cells. Panel (c) and (d) showed that TGF $\beta 1$ treatment led a reduction in the mRNA and protein expression of ZO-1 (Panel (c), column 2 and panel (d), column 2). These changes were attenuated by the overexpression of miRNA589 with treatment of pre-miRNA589 (Panel (c), column 3 and panel (d), column 3). The pre-miRNA589 partially reversed the TGF $\beta 1$-induced mRNA and protein expression of E-cadherin changes as well as ZO-1 (Panel (e), columns 2 and 3, and panel (f), columns 2 and 3). The level of ZO-1and E-cadherin was decreased, while the level of vimentin mRNA as well as protein were increased in HMrSV5 cells treated with TGF $\beta 1(5 \mathrm{ng} / \mathrm{ml}, 24 \mathrm{hr})$ (Panel (g), column 2 and panel (h), column 2), and this effect was abolished following the transfection with pre-miRNA589 (Panel (g), column 3, and panel (h) column 3). ${ }^{*} P<0.05$. versus control group, ${ }^{* *} P<0.05$ versus TGF- $\beta 1$ treated group. ${ }^{*} P<0.01$ versus control group. ${ }^{\#} P<0.01$ versus TGF- $\beta 1$ treated group.

a defined medium (1:1 mixture of DMEM and Ham's F12 containing $15 \%$ FBS, penicillin $(100 \mathrm{U} / \mathrm{ml})$, streptomycin $(100 \mu \mathrm{g} / \mathrm{ml})$, insulin $(0.5 \mu \mathrm{g} / \mathrm{ml})$, transferrin $(5 \mu \mathrm{g} / \mathrm{ml})$, and hydrocortisone $(1 \mu \mathrm{g} / \mathrm{ml}))$ at $37^{\circ} \mathrm{C}$ in a $5 \% \mathrm{CO}_{2}$ environment. After selection of stable transfectants, cells were maintained in a defined medium. After achieving $80 \%$ cell confluency, the medium was changed to FBS-free DMEM. Firstly, TGF $\beta 1(5 \mu \mathrm{g} / \mathrm{L})$ was added for different time $(0 \mathrm{hr}$, $12 \mathrm{hr}, 24 \mathrm{hr}$, and $48 \mathrm{hr}$ ) and level of miR589 was detected. Secondly, HMrSV5 cells were divided into three groups: control group (only FBS-free DMEM/F12), TGF- $\beta 1$ group (treated with TGF- $\beta 15 \mathrm{ng} / \mathrm{ml}$ for $24 \mathrm{~h}$ ), and pre-miR-589 + TGF- $\beta 1$ group (stably transfected with pre-miRNA589 by pretreating with pre-miR-589, and subjected to TGF$\beta 15 \mathrm{ng} / \mathrm{ml}$ for $24 \mathrm{~h}$ ). The mRNA and protein expression were determined by realtime PCR and western blotting procedures, respectively. The level of miRNA 589 was determined by realtime PCR. The morphology of HPMCs was investigated by inverted microscope.

2.3. Gene Expression. Total RNAs of HMrSV5 cells were isolated by trizol method. First-strand cDNAs were generated by two-step RT-PCR (Fermentas Life Science). Realtime PCR was performed in an applied biosystems 7300 realtime RCR system using a SYBR green PCR reagent kit (Invitrogen, Carlsbad, CA). The change in mRNA levels was determined by the formula $2^{-\left(\Delta \Delta \mathrm{C}_{\mathrm{T}}\right)}$, where $\Delta \mathrm{C}_{\mathrm{T}}$ is the value from the threshold cycle $\left(\mathrm{C}_{\mathrm{T}}\right)$ of the treated sample subtracted from the $\mathrm{C}_{\mathrm{T}}$ value of untreated or zero time-point control sample. The relative amount of mRNA in the sample was normalized to $\beta$-actin mRNA. The PCR primers were: Ecadherin sense: $5^{\prime}$-GTC ACT GAC ACC AAC GAT AAT CCT- $3^{\prime}$ and antisense: $5^{\prime}$-TTT CAG TGT GGT GAT TAC GAC GTT A-3', vimentin sense: $5^{\prime}$-TTG AAC GCA AAG TGG AAT C- $3^{\prime}$ and antisense: $5^{\prime}$-AGG TCA GGC TTG GAA ACA-3', ZO-1 sense: $5^{\prime}$-TGG TGT CCT ACC TAA TTC AAC TCA- $3^{\prime}$ and antisense: $5^{\prime}$-CGC CAG CTA CAA ATA TTC CAA CA- $3^{\prime}$.

2.4. Protein Expression. The protein expression was evaluated by western blotting procedures. The total protein of HMrSV5 cells was isolated with the use of RIPA lysis buffer containing a cocktail of protease inhibitors. Expression of $\mathrm{ZO}-1$, vimentin, and E-cadherin was assessed, using antiZO-1, vimentin, and E-cadherin antibodies (Stanta Cruz, $\mathrm{CA})$, respectively.

2.5. Immunofluorescence. Immunohistochemical staining of proteins was performed on HMrSV5 cells using anti-ZO1 and vimentin antibodies (Stanta Cruz, CA), respectively. HMrSV5 cells were grown on poly-L-lysine-coated glass coverslips (BD Biosciences, San Jose, CA) to $40 \%$ to $50 \%$ confluence, serum-deprived overnight (DMEM $+1 \%$ FBS), and then treated with TGF $\beta 1$ in the presence or absence of 
pretreatment for 5 hours with pre-miRNA589. After being fixed with acetone, cells were permeabilized in $1 \%$ Triton X100 (Sigma-Aldrich), and blocked with 5\% BSA. Cells were incubated with primary antibodies (ZO-1 and vimentin) overnight at $4^{\circ} \mathrm{C}$. Slides were then washed and incubated with the appropriate FITC-conjugated secondary antibody. Cells were then incubated with Hoechst 33342 (Invitrogen) for nuclear staining and mounted with propyl gallate under glass coverslips. Cells were then visualized for immunofluorescence with a laser scanning Nikon microscope at $\times 20$ magnification.

2.6. Pre-miRNA589 Transfection. Pre-miRNA transfection was widely used to decrease the level of target miRNA. The pre-miRNA589 (ABI), which mature production sequence was UGA GAA CCA CGU CUG CUC UGA G, was transfected in HMrSV5 cells with lipofectamine 2000 (Invitrogen).

2.7. Detection of miRNA589. We firstly determined the profile of miRNAs expression in HPMCs of PD patients and HMrSV 5 cells treated with TGF $\beta 1$ by Axon GenePix 4000B microarray (unpressed datas). miRNA589 was detected by realtime PCR. miRNAs of HMrSV5 cells were isolated by mrVana mRNA isolation kit (Ambion), and cDNA was synthesized using TaqMan micro RNA reverse transcription kit (ABI). Realtime PCR was performed in an applied biosystems 7300 Realtime RCR system using a university PCR master mix kit (ABI) and various TaqMan miRNA probes (ABI) based on the manufacturer's protocols. The change in miRNA levels was determined by the formula $2^{-\left(\Delta \Delta \mathrm{C}_{\mathrm{T}}\right)}$, where $\Delta \mathrm{C}_{\mathrm{T}}$ is the value from the threshold cycle $\left(\mathrm{C}_{\mathrm{T}}\right)$ of the treated sample subtracted from the $\mathrm{C}_{\mathrm{T}}$ value of untreated or zero time-point control sample. The relative amount of miRNA in the sample was normalized to U6.

2.8. Statistical Analysis. Data are expressed as the mean \pm $\mathrm{SE}$. The unpaired $t$-test was employed to assess the statistical differences between the two groups. $P$ values $<0.05$ were considered statistically significant.

\section{Results}

3.1. miRNA589 Expression in HPMCs of PD Patients. We first determined the level of miR589 in HPMCs of PD patients. As shown in Figure 1, decreased level of miRNA589 was obtained in HPMCs of PD patients compared to that of the control as assessed using realtime PCR with miRNA589 TaqMan probe.

3.2. miRNA589 Expression in HMrSV5 Cells Treated with TGF $\beta 1$. We first determined the profile of miRNAs expression in both HPMCs of PD patients and HMrSV5 cells treated with TGF $\beta 1$. HMrSV5 cells were exposed to TGF $\beta 1$ as indicated, and profile of miRNAs expression were assessed, too. Marked miRNA profile variation was obtained in both HPMCs of PD patients and HMrSV5 cells treated with TGF $\beta 1$ (unpressed data). TGF $\beta 1$ decreased the level of
miRNA589 of HMrSV5 cells in time-dependent manner, compared to the control as assessed using realtime PCR with miRNA589 TaqMan probe (Figure 2).

\subsection{Effect of Pre-miRNA589 on the miRNA589 Expression} in HMrSV5 Cells Subjected to TGF 1 1. HMrSV5 cells were transfected with pre-miRNA589 and then exposed to TGF $\beta 1$ $(5 \mathrm{ng} / \mathrm{ml})$ for $24 \mathrm{~h}$. The miRNA589 expression was assessed by realtime PCR with miRNA589 TaqMan probe. Treatment with TGF $\beta 1$ decreased expression of miR589 compared to that of the control (Figure 3). The decrease was not observed in cells transfected with pre-miRNA589, compared to the control. The TGF $\beta 1$-induced decreased expression of miRNA589 in HMrSV5 cells was abolished following transfection with pre-miRNA589.

3.4. Overexpression of miRNA589 Attenuates the EMT Changes in HMrSV5 Cells Subjected to TGF 31 . HMrSV5 cells were transfected with pre-miRNA589 and then exposed to TGF $\beta 1(5 \mathrm{ng} / \mathrm{ml})$ for $24 \mathrm{~h}$. ZO- 1 and vimentin mRNA and protein expression were assessed using realtime PCR, western blot and immunofluorescence, respectively. E-cadherin mRNA and protein expression were assessed using realtime PCR and western blot, respectively. As shown in Figure 4, treatment with TGF $\beta 1$ decreased the expression of $\mathrm{ZO}$ 1 (Figures 4(a) Row 2, 4(c) and 4(d)) as well as Ecadherin (Figures $4(\mathrm{e})$ and $4(\mathrm{f})$ ) compared to that of the control. The decrease was attenuated in cells transfected with pre-miRNA589 (Figures 4(a) Row 3, 4(c) and 4(d)). Treatment with TGF $\beta 1$ increased the expression of vimentin in HMrSV5 cells compared to that of the control (Figures 4(b) Row 2, 4(g) and 4(h)). The upregulation was inhibited in cell transfected with pre-miRNA589 (Figures 4(b) Row 3, $4(\mathrm{~g})$ and $4(\mathrm{~h}))$. This suggested that TGF $\beta 1$ induced EMT in HMrSV5 cells was blocked by upregulated miRNA589 level.

\section{Discussion}

In peritoneal dialysis research, a growing number of studies suggested that epithelial mesothelial transition (EMT) of HPMCs is a key potential mechanism for the development and progression of peritoneal fibrosis and UFF during longterm PD. TGF $\beta 1$ seemed to be the key factors in the induction of E-cadherin suppression and tight junction disaggregation, and that eventually leads to EMT. Recent studies have been mainly elucidated the intracellular signals transduction pathways in TGF- $\beta 1$-initiated EMT [16-18]. Even though, the molecular mechanism of which TGF- $\beta 1$ induces EMT of HPMCs is not yet fully understood and has been a major topic of current research on fibrosis. Surprisingly, evidence indicated that the most endogenous miRNAs are expressed in a highly tissue-specific manner and take centre stage in the EMT process. It has been reported that the miRNAs rapidly modulated by TGF- $\beta 1$ and a subset of eight miRNAs represent a particular signature of EMTlike response. However, nothing is known about miRNAs in peritoneal EMT process $[19,20]$. 
Remarkable miRNA profile variation was obtained in HPMCs treated with or without TGF $\beta 1$ exposure, which suggested miRNAs might correlate with EMT in HPMCs. Our data revealed that decreased miR589 in both HPMCs isolated from long-term PD patients' effluents. Similarly, a decreased expression of miR589 was seen in HMrSV5 cells treated with TGF $\beta 1$ as early as $12 \mathrm{hr}$, and lasting to $24 \mathrm{hr}$ and $48 \mathrm{hr}$ in time-dependent manner, which was confirmed by microarray analysis and realtime PCR. The decreased level of miRNA589 in HMrSV5 cells treated with TGF $\beta 1$ was inhibited by transfection of pre-miR589, which suggested miRNA589 could be downregulated by TGF $\beta 1$. Furthermore, to determine the role of miRNA589 in TGF $\beta 1$ induced EMT, HMrSV5 cells were transfected with premiR589 then exposed to TGF $\beta 1$. The results showed an inhibition of EMT induced by TGF $\beta 1$, which suggested miRNA589 might play a role in TGF $\beta 1$ induced EMT in HMrSV5 cells. It remains unknown whether miR589 mediated peritoneal fibrosis in vivo. Due to time constraints, we do not have the PD mice model available yet, which should be presented in the future.

In summary, we have determined that miRNA589 expression is downregulated in HMrSV5 cells exposed to TGF $\beta 1$. There is emerging evidence that miRNAs might be a novel class of potential therapeutic targets for various chronic diseases. Further studies should be conducted to determine the target mRNA of miRNA589 involved in EMT process and to delineate the relationship between miRNA589 expression and EMT comprehensively. We believe that an understanding about whether miRNA589 is critical to the EMT of HPMC initiation will lead to the development of more effective diagnostic markers and therapies for UFF in PD patients.

\section{References}

[1] L. S. Aroeira, A. Aguilera, R. Selgas et al., "Mesenchymal conversion of mesothelial cells as a mechanism responsible for high solute transport rate in peritoneal dialysis: role of vascular endothelial growth factor," American Journal of Kidney Diseases, vol. 46, no. 5, pp. 938-948, 2005.

[2] P. Patel, J. West-Mays, M. Kolb, J. C. Rodrigues, C. M. Hoff, and P. J. Margetts, "Platelet derived growth factor B and epithelial mesenchymal transition of peritoneal mesothelial cells," Matrix Biology, vol. 29, no. 2, pp. 97-106, 2010.

[3] M. Yáñez-Mó, E. Lara-Pezzi, R. Selgas et al., "Peritoneal dialysis and epithelial-to-mesenchymal transition of mesothelial cells," New England Journal of Medicine, vol. 348, no. 5, pp. 403-413, 2003.

[4] J. Loureiro, A. Aguilera, R. Selgas et al., "Blocking TGF$\beta 1$ protects the peritoneal membrane from dialysate-induced damage," Journal of the American Society of Nephrology, vol. 22, no. 9, pp. 1682-1695, 2011.

[5] P. J. Margetts, P. Bonniaud, L. Liu et al., "Transient overexpression of TGF- $\beta 1$ induces epithelial mesenchymal transition in the rodent peritoneum," Journal of the American Society of Nephrology, vol. 16, no. 2, pp. 425-436, 2005.

[6] R. Vargha, M. Endemann, K. Kratochwill et al., "Ex vivo reversal of in vivo transdifferentiation in mesothelial cells grown from peritoneal dialysate effluents," Nephrology Dialysis Transplantation, vol. 21, no. 10, pp. 2943-2947, 2006.

[7] X. Wang, J. Nie, Z. Jia et al., "Impaired TGF- $\beta$ signalling enhances peritoneal inflammation induced by E. Coli in rats," Nephrology Dialysis Transplantation, vol. 25, no. 2, pp. 399412, 2010.

[8] V. Ambros, "microRNAs: tiny regulators with great potential," Cell, vol. 107, no. 7, pp. 823-826, 2001.

[9] J. A. Birchler and H. H. Kavi, "Molecular biology: slicing and dicing for small RNAs," Science, vol. 320, no. 5879, pp. 10231024, 2008.

[10] A. Khvorova, A. Reynolds, and S. D. Jayasena, "Functional siRNAs and miRNAs exhibit strand bias," Cell, vol. 115, no. 2, pp. 209-216, 2003.

[11] C. S. Tellez, D. E. Juri, K. Do et al., "EMT and stem celllike properties associated with miR-205 and miR-200 epigenetic silencing are early manifestations during carcinogeninduced transformation of human lung epithelial cells," Cancer Research, vol. 71, no. 8, pp. 3087-3097, 2011.

[12] B. Wang, P. Koh, C. Winbanks et al., "MiR-200a prevents renal fibrogenesis through repression of TGF- $\beta 2$ expression," Diabetes, vol. 60, no. 1, pp. 280-287, 2011.

[13] C. Vandewalle, J. Comijn, B. De Craene et al., "SIP1/ZEB2 induces EMT by repressing genes of different epithelial cellcell junctions," Nucleic Acids Research, vol. 33, no. 20, pp. 6566-6578, 2005.

[14] M. Kato, J. Zhang, M. Wang et al., "MicroRNA-192 in diabetic kidney glomeruli and its function in TGF- $\beta$-induced collagen expression via inhibition of E-box repressors," Proceedings of the National Academy of Sciences of the United States of America, vol. 104, no. 9, pp. 3432-3437, 2007.

[15] P. A. Gregory, A. G. Bert, E. L. Paterson et al., "The miR200 family and miR-205 regulate epithelial to mesenchymal transition by targeting ZEB1 and SIP1," Nature Cell Biology, vol. 10, no. 5, pp. 593-601, 2008.

[16] J. Loureiro, M. Schilte, A. Aguilera et al., "BMP-7 blocks mesenchymal conversion of mesothelial cells and prevents peritoneal damage induced by dialysis fluid exposure," Nephrology Dialysis Transplantation, vol. 25, no. 4, pp. 1098-1108, 2010.

[17] P. Patel, Y. Sekiguchi, K. H. Oh, S. E. Patterson, M. R. J. Kolb, and P. J. Margetts, "Smad3-dependent and-independent pathways are involved in peritoneal membrane injury," Kidney International, vol. 77, no. 4, pp. 319-328, 2010.

[18] Q. Liu, H. Mao, J. Nie et al., "Transforming growth factor $\beta 1$ induces epithelial-mesenchymal transition by activating the JNK-SMAD3 pathway in rat peritoneal mesothelial cells," Peritoneal Dialysis International, vol. 28, supplement 3, pp. S88-S95, 2008.

[19] H. Acloque, J. P. Thiery, and M. A. Nieto, "The physiology and pathology of the EMT. Meeting on the Epithelialmesenchymal transition," EMBO Reports, vol. 9, no. 4, pp. 322-326, 2008.

[20] M. Korpal and Y. Kang, "The emerging role of miR-200 family of microRNAs in epithelial-mesenchymal transition and cancer metastasis," RNA Biology, vol. 5, no. 3, pp. 115$119,2008$. 


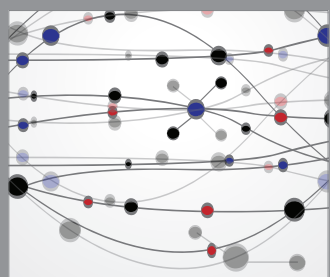

The Scientific World Journal
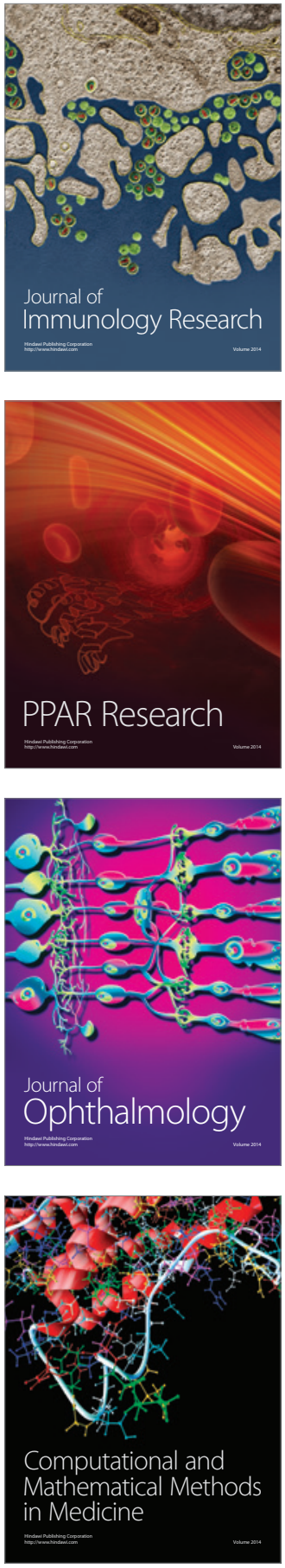

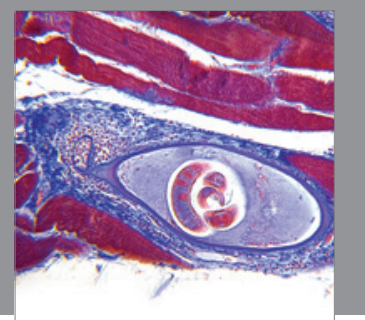

Gastroenterology

Research and Practice
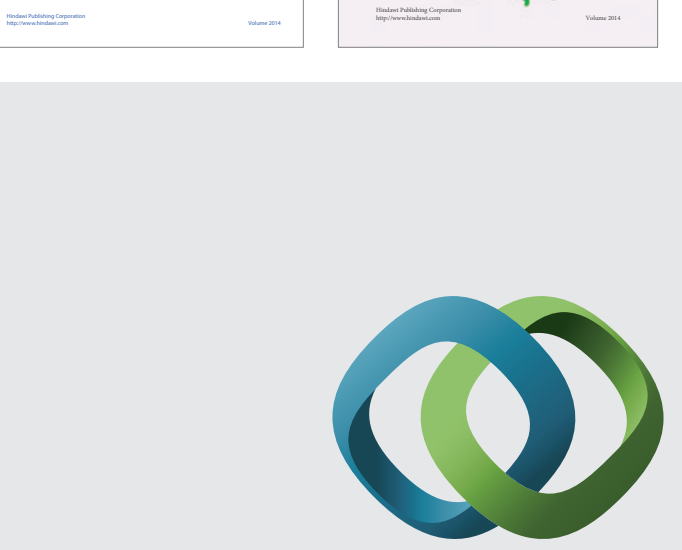

\section{Hindawi}

Submit your manuscripts at

http://www.hindawi.com
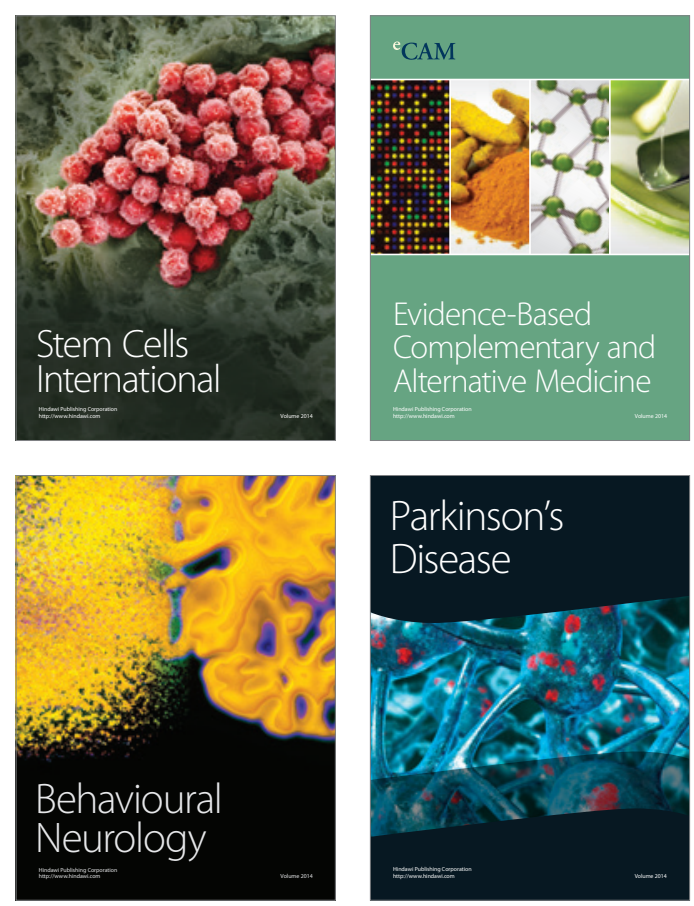

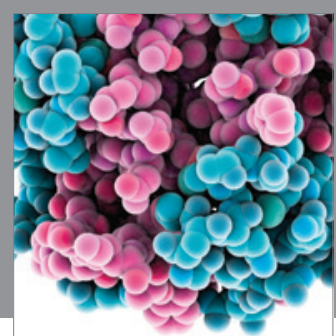

Journal of
Diabetes Research

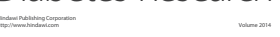

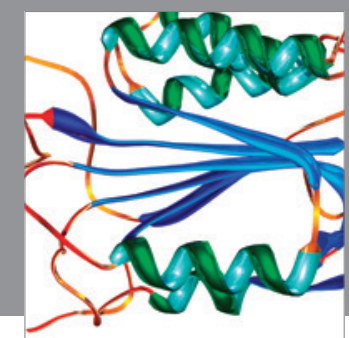

Disease Markers
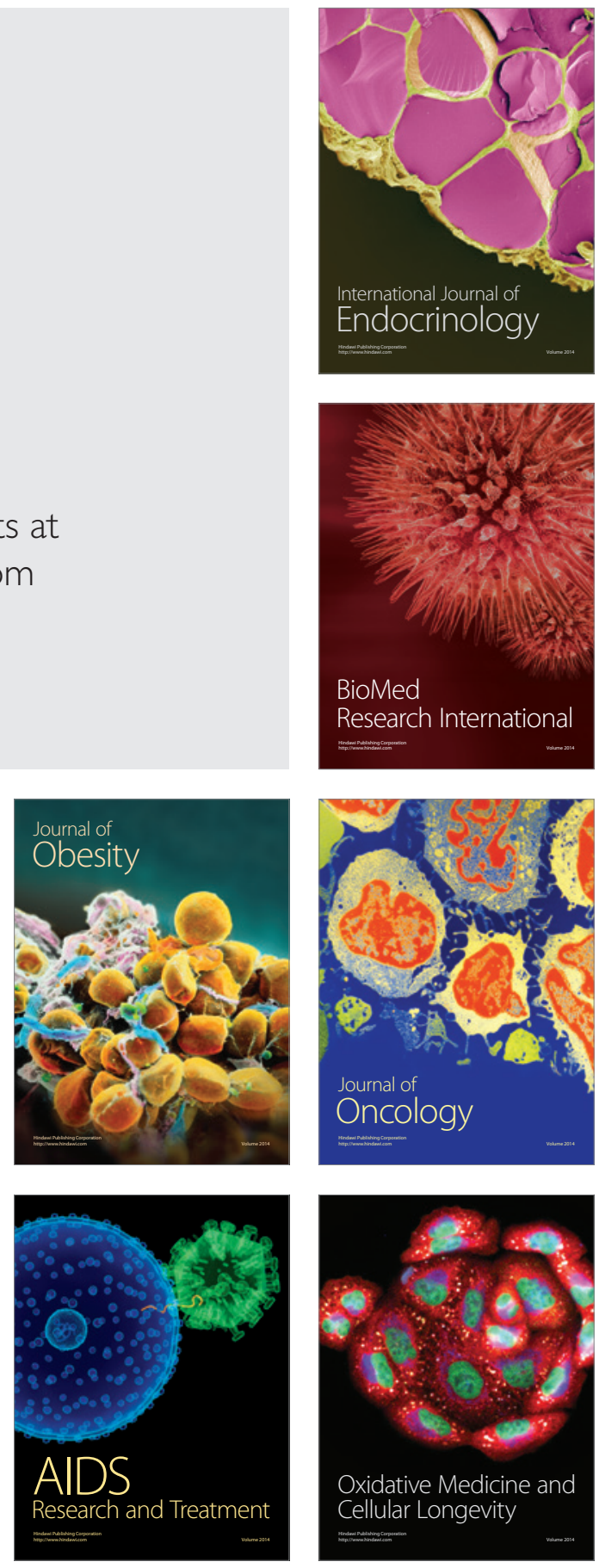